\title{
Strategies for Disease Prevention and Health Promotion in Urban Areas: The Erice 50 Charter
}

\author{
D. D’Alessandro ${ }^{1}$, S. Arletti ${ }^{2}$, A. Azara ${ }^{3}$, M. Buffoli ${ }^{4}$, L. Capasso 5 , A. Cappuccitti ${ }^{1}$,
} A. Casuccio ${ }^{6}$, A. Cecchini ${ }^{3}$, G. Costa ${ }^{7}$, A.M. De Martino ${ }^{8}$, M. Dettori ${ }^{3}$, E. Di Rosa ${ }^{9}$, G.M. Fara ${ }^{1}$, M. Ferrante ${ }^{10}$, G. Giammanco ${ }^{10}$, A. Lauria ${ }^{11}$, G. Melis ${ }^{12}$, U. Moscato ${ }^{13}$, I. Oberti ${ }^{4}$, C. Patrizio ${ }^{1}$, M.G. Petronio ${ }^{14}$, A. Rebecchi ${ }^{4}$, V. Romano Spica ${ }^{15}$, G. Settimo ${ }^{16}$, C. Signorelli ${ }^{17}$, S. Capolongo ${ }^{4}$, and the attendees* of the 50th Course "Urban Health. Instruments for promoting health and for assessing the hygienic and sanitary conditions in urban areas"

Keywords: Urban Health, Public Health, Built Environment, Planning and Designing Strategies, Health Promotion

Parole chiave: Salute Urbana, Salute Pubblica, Ambiente Costruito, Strategie di Pianificazione e Progettazione, Promozione della Salute

\footnotetext{
${ }^{1}$ Sapienza Università di Roma, Rome, Italy

${ }^{2}$ Rete Italiana Città Sane, Modena, Italy

${ }^{3}$ Università degli Studi di Sassari, Sassari, Italy

${ }^{4}$ Politecnico di Milano, Milan, Ital

${ }^{5}$ Università degli Studi di Pavia, Pavia, Italy

${ }^{6}$ Università degli Studi di Palermo, Palermo, Italy

${ }^{7}$ Università degli Studi di Torino, Turin, Italy

${ }^{8}$ Ministero della Salute, Rome, Italy

${ }^{9}$ Azienda Sanitaria Locale Roma 1, Rome, Italy

${ }^{10}$ Università degli Studi di Catania, Catania, Italy

${ }^{11}$ Unità Sanitaria Locale 20 Verona, Verona, Italy

${ }^{12}$ Istituto Superiore sui Sistemi Territoriali per l'Innovazione (SiTI), Turin, Italy

${ }^{13}$ Università Cattolica del Sacro Cuore, Rome, Italy

${ }^{14}$ Unità Sanitaria Locale 11 Empoli, Empoli, Italy

${ }^{15}$ Università di Roma "Foro Italico", Rome, Italy

${ }^{16}$ Istituto Superiore di Sanità (ISS), Rome, Italy

${ }^{17}$ Università degli Studi di Parma, Parma, Italy
}

* Attendees of the Course and contributors to the discussion and preparation of the The Erice 50 Charter

V Alessi ${ }^{1}, \mathrm{~F}_{\text {Apollonio }}{ }^{2}$, E Barbagallo ${ }^{18}$, AM Bassot ${ }^{3}$, D Bernini ${ }^{17}$, A Borghini $^{13}$, M Borri $^{9}$, A Brandimarte $^{9}, \mathrm{C} \mathrm{Copat}^{10}, \mathrm{M}^{2}$ Cracchiolo $^{6}$, S Cribellati ${ }^{4}$, A Cristaldi ${ }^{10}, \mathrm{P} \mathrm{D}^{\prime}$ Agati $^{10}$, A D' Amico ${ }^{19}$, A De Marchis ${ }^{9}$, M Dell'Ovo ${ }^{4}$, AM Donia ${ }^{5}$, T Filippini ${ }^{6}$,

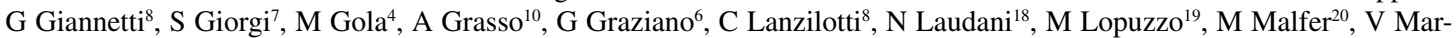
chese $^{6}$, A Marzella ${ }^{19}$, A Mascarello ${ }^{20}$, GM Milicia ${ }^{17}$, P Nurchis ${ }^{9}$, S Ogana ${ }^{3}$, CG Oliveri Conti ${ }^{10}, \mathrm{C} \mathrm{Pacifico}^{19}, \mathrm{~S}$ Paduano $^{23}, \mathrm{~L}$ Paglione $^{1}$, S Palmeri ${ }^{6}$, G Pieve ${ }^{24}$, M Raffo 9 , G Raguzzoni ${ }^{10}$, DD Raia ${ }^{6}$, A Righi ${ }^{4}$, A Rochira ${ }^{26}$, L Rondinelli ${ }^{17}, \mathrm{C} \mathrm{Salvia}^{23}$, R Sciaraffa $^{13}, \mathrm{~F}_{\text {Trogu }}{ }^{3}$, A Ubiali ${ }^{26}$, R Valt ${ }^{20}$, V Vantaggiato ${ }^{25}$, G Ventura $^{6}$, P Zuccarello ${ }^{10}$

${ }^{1}$ Sapienza Università di Roma, Rome, Italy

${ }^{2}$ Rete Italiana Città Sane, Modena, Italy

${ }^{3}$ Università degli Studi di Sassari, Sassari, Italy

${ }^{4}$ Politecnico di Milano, Milan, Italy

${ }^{5}$ Università degli Studi di Pavia, Pavia, Italy

${ }^{6}$ Università degli Studi di Palermo, Palermo, Italy

${ }^{7}$ Università degli Studi di Torino, Turin, Italy 


\begin{abstract}
The Erice 50 Charter titled "Strategies for Diseases Prevention and Health Promotion in Urban Areas" was unanimously approved at the conclusion of the 50th Residential Course "Urban Health. Instruments for promoting health and for assessing hygienic and sanitary conditions in urban areas", held from 29th March to 2nd April 2017 in Erice, at the "Ettore Majorana" Foundation and Centre for Scientific Culture and promoted by the International School of Epidemiology and Preventive Medicine "G. D'Alessandro" and the Study Group "Building Hygiene” of the Italian Society of Hygiene, Preventive Medicine and Public Health (SItI).

At the conclusion of the intense learning experience during the Course, with more than 20 lectures, workshops and long-lasting discussions between Professors and Students, the participants identified the major points connecting urban features and Public Health, claiming the pivotal role of urban planning strategies for the management of Diseases Prevention and Health Promotion activities. The Erice 50 Charter is configured as a Decalogue for Healthy Cities and as a Think Tank for designing effective strategic actions and best practices to develop urban regeneration interventions and improve the urban quality of contemporary cities.

The Decalogue is structured into the following key strategic objectives: 1. Promoting urban planning interventions that address citizens towards healthy behaviours; 2. Improving living conditions in the urban context; 3. Building an accessible and inclusive city, with a special focus on the frail population; 4 . Encouraging the foundation of resilient urban areas; 5. Supporting the development of new economies and employment through urban renewal interventions; 6. Tackling social inequalities; 7. Improving stakeholders' awareness of the factors affecting Public Health in the cities; 8. Ensuring a participated urban governance; 9. Introducing qualitative and quantitative performance tools, capable of measuring the city's attitude to promote healthy lifestyles and to monitor the population's health status; 10. Encouraging sharing of knowledge and accessibility to informations.

Finally, all the participants underlined that a multidisciplinary team, composed of Physicians specialized in Hygiene, Preventive Medicine, Public Health and Technicians as Architects, Urban planners and Engineers, is needed to deepen the research topic of Urban Health.
\end{abstract}

\footnotetext{
${ }^{8}$ Ministero della Salute, Rome, Italy

${ }^{9}$ Azienda Sanitaria Locale Roma 1, Rome, Italy

${ }^{10}$ Università degli Studi di Catania, Catania, Italy

${ }^{11}$ Unità Sanitaria Locale 20 Verona, Verona, Italy

${ }^{12}$ Istituto Superiore sui Sistemi Territoriali per l'Innovazione (SiTI), Turin, Italy

${ }^{13}$ Università Cattolica del Sacro Cuore, Rome, Italy

${ }^{14}$ Unità Sanitaria Locale 11 Empoli, Empoli, Italy

${ }^{15}$ Università di Roma "Foro Italico", Rome, Italy

${ }^{16}$ Istituto Superiore di Sanità (ISS), Rome, Italy

${ }^{17}$ Università degli Studi di Parma, Parma, Italy

${ }^{18}$ Università degli Studi di Messina, Messina, Italy

${ }^{19}$ Università degli Studi di Bari "Aldo Moro", Bari, Italy

${ }^{20}$ Azienda Sanitaria dell'Alto Adige, Trento, Italy

${ }^{21}$ SEGE Service Design Per L'impresa, Milan, Italy

${ }^{22}$ Università degli Studi dell'Aquila, L'Aquila, Italy

${ }^{23}$ Università degli Studi di Modena e Reggio Emilia, Modena, Italy

${ }^{24}$ Università degli Studi di Pisa, Pisa, Italy

${ }^{25}$ Azienda Sanitaria Locale di Lecce, Lecce, Italy

${ }^{26}$ Azienda Sanitaria Locale di Cagliari, Cagliari, Italy

${ }^{27}$ Università di Bologna, Bologne, Italy
} 


\section{The Charter}

At the end of the 50th course of the "International School of Epidemiology and Preventive Medicine G D'Alessandro" devoted to "Urban Health. Instruments for promoting health and for assessing the hygienic and sanitary conditions in urban areas", held in Erice from March $29^{\text {th }}$ to April $2^{\text {nd }} 2017$, both Professors and Attendees unanimously highlight the key role of urban planning as a fundamental support for healthy and sustainable lifestyles and for reducing inequalities in health conditions. Therefore, they approve unanimously The Erice 50 Charter, titled "Strategies for Diseases Prevention and Health Promotion in Urban Areas."

\section{Introduction}

Health refers to an individual and collective status, strongly influenced by the environmental context and by general and local governmental policies and is not merely an issue that exclusively concerns its promotion and protection $(1,2)$. The connection between morphological and functional features of the urban context and Public Health is a crucial and contemporary aspect, considering the urban drift that defines modern societies nowadays. Urbanization and city shaping provide substantial opportunities for Public Health promotion and protection, but can also bear risks (1). These risks represent a main concern for the National Health Systems and, in general, for Public Institutions (3), because of the large fraction of population potentially involved: the population density which characterises urban areas changes Public Health perspectives in terms of both issues and possible solutions $(1,2,4)$. From the Ottawa Charter (5) and the strategies "Health in All Policies" (6), environment and living spaces have been considered a global, social and political entity determining Health. In particular, globalisation and urbanisation, combined with an ageing population, interact with social, cultural and economic health determinants (education, living and working spaces) exposing people to behavioural health risk factors (smoking, unhealthy eating habits, limited physical activity, alcohol abuse, etc.), which can determine chronic and degenerative diseases (2, 7-9).

Environmental policies are also among the indirect determinants of chronic and degenerative diseases, often defined as "causes of causes" (10). The burden of deaths, disease and disability related to major illnesses may indeed be reduced, year after year, through appropriate environmental and cross-sectorial policies aimed at reducing the exposure that are detrimental to health, as already underlined in the WHO-Europe Report Action Plan for implementation of the European Strategy for prevention and control of non-communicable diseases 2012-2016 (11).

In general, urban environment has an impact on health by acting on several factors (1):

- modifying the population's lifestyle as a consequence of social and economic changes induced by urbanisation (e.g. wide availability of unhealthy food and beverages, easy access to psychoactive substances, prostitution, gambling, etc.), which could have negative impacts on health, such as overweight and obesity, social isolation, mental illness, infectious diseases, etc;

- exposing the population to risks related to a polluted environment (e.g. atmospheric emissions linked to domestic activities and vehicular traffic, noise, lack of green areas (12) and pedestrian paths, excess of vehicular traffic etc.), which could have negative impacts on health, such as respiratory, neurodegenerative and cardiovascular diseases, overweight and obesity, road accidents; 
- altering the life-support systems of the biosphere for the important ecological footprint of modern urban populations (e.g. climate change), which could have negative impacts on health due to thermal distress, natural disasters and changes in the ecosystem.

On the other hand, if the cities are well planned, organised and managed, benefits may widely exceed the risks, allowing every individual to express one's potential and to respond positively to the opportunities of everyday life (1). Therefore, considering cities as a health enhancer is crucial. Landscape and urban planning, on both large and small scale, may be regarded as the key instrument towards protecting and promoting individual and population health $(7,13)$. It is therefore a priority to assess and address conscious design and project choices, in order to limit health risk factors to protect citizens' wellbeing (7, 14). In this context, in Italy, it is important to point out how the National Prevention Plan (PNP) 2014-2018 (15) assigns to Prevention Departments of Local Health Authorities the governance of an integrated network among different stakeholders, in order to generate mutual interactions between local communities and regional and national institutions (16). Among the PNP strategies, health promotion programs are planned, in order to create favourable conditions (healthy behaviours) based on an inter-sectorial approach (e.g. educational and social policies, urban, territorial and transports planning etc.) involving all the actors, moving from political decision-makers down to local authorities (community empowerment). In fact, according to PNP 2014-2018, inter-sectorial collaboration allows more effective, efficient and sustainable actions on health determinants, in comparison to those undertaken only by the healthcare sector.

\section{Aims}

The strategy "Health in All Policies" (6) has clearly highlighted that health does not only depend on providing health services and on individual lifestyles, but especially on environmental quality, working conditions and living standards, (urban) people's capabilities (17-19), community cohesion and quality of public services of different kinds. Many of these factors are influenced by a correct planning and management of the living environment. In the 2006, WHO Report "Preventing disease through healthy environments: Towards an estimate of the environmental burden of disease" (20), the following areas of interest are identified as priorities: (a) climate change and sustainable development; (b) exposure to the main risk factors: pollution and inadequate housing conditions; (c) information on environmental health and risks communication; (d) natural resources management.

\section{The key points}

According to the above premises, this document defines the strategic goals for the realization of a "Healthy City" by local governments.

\section{Promoting urban planning interven- tions that address citizens towards healthy behaviours}

The organization and, more generally, the social and environmental context, can influence and change emerging needs, life-styles and individual expectations (2). Strategic urban planning is useful to promote the adoption of healthy lifestyles (21-23) through the requalification of existing areas and the design of new settlements.

Practical and feasible actions that could be adopted are listed here:

- to give priority to urban policies oriented to reduce soil consumption; 
- to encourage green belts, green corridors and green spaces and give special protection to existing green areas;

- to achieve a well-balanced distribution of functions in order to favour the functional mix of the city;

- to design cities able to foster public transports and active mobility (24), also through the improvement of walkability of places $(25,26)$ and the realization of safe and well connected streets and cycle paths;

- to design high-quality places and systems of public spaces that encourage socialization and physical activity taking into account specific needs of the most vulnerable part of the population;

- to optimize the sustainable cycle of solid wastes disposal;

- to promote interventions for overcoming the architectural barriers by implementing plans for their removal;

- to ensure a diversified offer of healthy, safe and affordable food;

- to provide suitable and equally distributed public services, especially regarding healthcare, social and educational structures;

- to provide compensation areas for extreme wheater events.

\section{Improving living conditions in the urban context}

High standards of health are ensured by the improvement of houses and housing conditions, the control of indoor and outdoor pollution, the access to energy, water and suitable purification systems as well as proper waste disposal. Furthermore, these factors reduce the risk of emerging and re-emerging infectious, chronic and degenerative diseases. $(2,8,9,27)$. Many of these issues mainly affect abusive settlements, which sometimes represent an unavoidable solution for some outcast population groups like people under critical economic conditions and social exclusion (28). These kinds of settlements are very seldom provided with services. be adopted are listed here:
- to improve housing conditions;
- to promote actions at municipal level fostering the re-functionalization of neglected areas and the recovery of unused, existing buildings to be devoted to social housing;

- to arrange the services necessary to settlement, with a special regard to the public supply of drinking water and hygienic services suitable and accessible for everyone;

- to enhance systems for water differentiation, recovery and recycling (both at meteorological and domestic level);

- to promote waste recycling with appropriate home recovery systems and using building materials and products from the recycling industry;

- to place categories at major risk of social marginalization into socio-sanitary plans;

- to implement measures for the limitation of indoor and outdoor air pollution;

- to extend the use of technologies for environmental sustainability in order to reduce consumption and pollution;

- to define measures against energetic inefficiency (e.g. bonus or tax incentives) (29).

\section{Building an accessible and inclusive city, with a special focus on the frail population}

In Italy, as everywhere in the world, the population is quickly getting older. With increasing age, many elderly people will develop physical and sensory disability (2, 8). On these issues, the WHO delivered an orientation paper, mainly addressed to town planners, with the purpose of monitoring progress towards an "elderly-friendly city". Such a city encourages an active aging and optimizes the opportunities of health, safety and participation with the goal of improving the quality of elderly life $(2,30)$. Basically, the city adapts its buildings, open spaces and 
services in order to make them accessible to frail people who have many needs and few capabilities (2). Solutions like these clearly fulfil also many needs of the non-elderly frail part of the population, for instance children or people with different functional limitations.

\section{Practical and feasible actions that could} be adopted are listed here:

- to design an urban landscape elderlyand children-friendly, thereby facilitating socialization;

- to adopt policies directed to overcome architectural barriers;

- to make public transport accessible to people with functional limitations;

- to make streets in the neighbourhoods easily viable not only for pedestrians but also for bicycles and pushchairs;

- to predict an appropriate number of seats along the streets;

- to develop the walkability of places by providing shades and shelters; to improve public lighting; to design streets and intersections in order to integrate footpaths with the surrounding urban spaces; to increase pedestrian comfort, to protect pedestrians from the car traffic; to invest in maintenance and street furniture $(22,26$, 31);

- to make a sufficient number of public toilets available, adding an appropriate number of drinking fountains;

- to foster associations for a more active life (sport for everyone).

\section{Encouraging the foundation of resilient urban areas}

Cities determine a remarkable pressure on the biosphere, inducing modifications harmful for both environment and health, among them climate change (1). Studies on heat- and cold-waves in the past few years have highlighted significant increases in mortality trends, involving primarily the most vulnerable subjects $(32,33)$. Recently, many cities faced complex emergencies, such as natural disasters and social crises. Making urban environment resilient, namely able to support population, organisations and frail segments of the society in order to resist to disruptive events (34), is a key element for local governments to develop quick response to these events. Resilience does not imply restoring an earlier state, but just the basic functionality through adaptation. This could help to reduce the risks caused by disaster on an urban scale, preparing for emergencies, evaluating coordinated response capabilities at a national, regional and local level.

Practical and feasible actions that might be implemented include:

- to increase built environment resilience (35);

- to avoid the Urban Sprawl phenomenon understood to be the dissemination of new construction sites in isolated areas, separated from other densely built environments by non-urbanized areas;

- to contain the Shrinking City phenomenon, understood to be the demographic contraction of the city in favour of peripheral suburbs and municipal boundaries, with serious consequences on the management of infrastructure systems;

- to forbid urban modifications, including new constructions in high-risk area;

- to guide urban planning in order to reduce urban vulnerabilities;

- to promote the shift from grey to green and blue economies at an urban scale (12);

- to identify healthcare structures in safe areas to manage emergencies;

- to identify structures and strategies to manage climate emergencies (extreme cold and hot weather);

- to identify spaces to be destined to temporary lodging/housing;

- to strengthen community education and ability to respond to emergency situations;

- to improve surveillance of the health effects of catastrophes. 


\section{Supporting the development of new economies and employment through urban renewal interventions}

Recent statistics appear to underline a modest reduction of unemployment in Italy; nevertheless, this issue is still really relevant across the nation, showing sensible differences with respect to age, gender and area (8). In the past few years, urban regeneration has widened its approach, not only to give to cities a new and more competitive look, but also to boost cultural, economical, and social aspects, taking into account environmental and space needs. This implies completely different choices, complying with new development models, able to generate wellness and wealth from recycling and regenerating resources. To make this happen, a radical change is needed, involving public institutions, economic stakeholders, and individuals.

Practical and feasible actions that might be implemented include:

- to encourage the connections with the past, the local cultural and natural heritage;

- to facilitate connections in order to organise and analyse data on environmental health determinants;

- to promote co-working and sustainable commerce;

- to promote biological agriculture on a local scale;

- to support information accessibility and cities digitalisation;

- to support local entrepreneurship and public-private collaborations:

- to support reconversion of working spaces in order to promote employment;

- to implement job opportunities for new generations and improve working conditions for the elderly, to promote inter-generational solidarity and healthy aging.

\section{Tackling social inequalities}

The city often presents, in its forms and spatial arrangements, social inequalities, characterized by different distribution of social determinants of health: education, income, work, relational goods and culture $(13,28)$. In our cities, we see a distribution disproportion between downtown and suburbs, or between historical and consolidated suburbs and those newly built, or even between neighbourhoods planned according to a social and inclusive urban design and those left to their own fate (9). The need to re-imagine urban territory through social ties and to regenerate neighbourhoods from marginal ghettos to daily life sharing places, forces us to rethink also the conventional tools of Urban Planning and Public Health, integrating knowledge and skills of different spheres (16). We must precisely focus the intervention on the indissoluble link between built, social and lifetime environment both in terms of study, deepening and transformation.

Practical and feasible actions that might be implemented include:

- to encourage the use of qualitative and quantitative instruments and methodologies for studying socioeconomic and integrated health dynamics and for evaluating impacts of plans, projects and policies in order to reduce the inequalities in people's health, wellbeing and capabilities (26);

- to involve all stakeholders in the decision-making process of changing and transforming the urban context, with particular reference to the most disadvantaged communities;

- to strengthen social networks in the most vulnerable areas;

- to inform and train informal communities about the socioeconomic characteristics of their territory;

- to encourage Advocacy among the Local Institutions regarding the need for peripheral urban space-building interventions;

- to regenerate disused and / or abandoned spaces, creating shared sites of aggregation which increase the individual feeling of belonging to the community and its resilience; 
- to pay attention to the most vulnerable population groups, identifying characteristics and needs useful for future interventions on the urban context aimed at improving their use and liveability and people's capabilities.

\section{Improving stakeholders' awareness} of the factors affecting Public Health in the cities

Today, the education to sustainable development and, above all, to the management of a "one health-care" environment, is a strategic goal of present and future urban areas $(1,10)$. The environmental challenge, linked to land resources conservation, is no longer elusive to ensure adequate levels of life quality for future generations. This is particularly relevant to the daily choices, which affect not only the management and use of our home, but also of the whole urban life context.

Practical and feasible actions that might be implemented include:

- to increase the stakeholders awareness of the proper maintenance and management of buildings, the choice of low emission materials, the proper use of indoor equipment and facilities;

- to increase the awareness of the potential environmental impact produced by improper buildings management;

- to implement resilience to emergencies and natural disasters;

- to promote active mobility and the use of public transport in the whole population, especially in school age and in general towards urban soft mobility choices, which are more efficient from an economic, environmental and health impact point of view;

- to facilitate the training of operators in management of health emergencies;

- to train the operators on new territory design tools (e.g. regeneration).

\section{Ensuring a multi-sector urban governance}

At the urban level, good health governance can ensure more equally distributed opportunities and benefits, as well as facilitate fair access to healthcare. However, we should keep in mind that many causes of bad health do not fall under the direct control of the health sector, and the implementation of crosssectorial approaches is necessary for their prevention $(2,6,10)$. Local governments can exercise direct influence on many health determinants, through housing and transport policies, tobacco regulations and food policies, addressing land use and issuing rules towards the adoption and application of health promotion standards. A good urban governance should also be sustainable, paying attention to problems and planning horizons, which extend beyond current needs.

Practical and feasible actions that might be implemented include:

- to share the city's health planning informations;

- to involve the stakeholders (institutional and non-institutional) in all the stages of the decision-making process;

- to encourage dialogue and confrontation between the various professionals involved;

- to create public participation opportunities at all levels;

- to encourage active citizen participation in making choices.

9. Introducing qualitative and quantitative performance tools, capable of measuring the city's attitude to promote healthy lifestyles and to monitor the population's health status

In contemporary urban contexts, policymakers and stakeholders involved in urban planning and Public Health protection and promotion are targeting economic resources and research in Evidence Based Urban Planning Actions for Health. Processes of validation, monitoring, evaluation and formulation of forecast scenarios, through the application of calculation tools and models, 
are the basis of city regeneration actions as well as urbanized territory governance (36). Forward-looking reasoning, based on analyses and data collection, is a pivotal action of the new design approach aimed to identify Community Based Design Strategies.

Practical and feasible actions that might be implemented include:

- to conduct surveys aimed at determining the urban quality perceived by the population and controlling the environmental components;

- to design observational studies aimed at qualitatively identifying the urban conditions and the elements both problematic and representing emerging potentialities;

- to collect information through environmental ecological studies with the aim to determine quantitative data on accessibility aspects, transport, provision of services, functional mix level and other features of the city;

- to define a multi-criteria approach to analyse and describe the problem, by identifying quantitative-qualitative evaluation alternatives and choices;

- to develop both specialised and integrated operational decision and design support systems for the urban planning for health;

- to monitor the population health status, with particular reference to urbanrelated illnesses, both infectious and noncommunicable, and to lifestyles, with special regard to the missed opportunities to promote physical activity in the urban or building-related context;

- to use forecasting models for assessing the positive effects of new settlements in regeneration and/or redesign actions of urban areas.

\section{Encouraging sharing of knowledge and accessibility to information}

Fast urbanization and the consequent growth of social and sanitary issues imply the need to establish new approaches to the promotion of Public Health, which are technologically innovative and adapted to contemporary lifestyles. The work of policy makers and all those involved in the planning process and socio-assistance management is crucial to ensure awarenessraising actions and the development of participatory processes. Lastly, participation is fundamental in the communities, especially the poorest ones, where sometimes the ability to be politically determinant and to gain a role in design are limited.

$\frac{\text { be implemented include: }}{\bullet \text { to establish greater interconnection }}$ between the different disciplines involved, from technical training (architects, engineers and urban planners) to healthcare professionals (physicians specialised in Hygiene, Health Technicians, Health Visitors) (37);

- to interpret the opportunities to disseminate information through IT platforms, mobile devices (thanks to their spread due to their cheapness) and the birth of the Internet of Things concept;

- to develop technological tools capable of expanding the statistical basis, with particular reference to the data-collection phase;

- to develop computer systems able to relate endogenous factors influencing health conditions with the individual, facilitating the task of public healthcare providers;

- to compare a variety of case studies, with the aim of underlining both problems and potentialities in order to define bestpractices exportable also to other contexts.

- to bring the researches' results closer to the population's knowledge, creating smart web platform as privileged places of science easy to be accessed and understood.

\section{Conclusions and hints for future research}

Recent evidence shows that chronic degenerative diseases cause $86 \%$ of deaths and $77 \%$ of the burden of diseases within 
the European Region (38). Among health determinants, environmental and behavioural risk factors play a major role in the overall health balance. Changes in lifestyle and diet contribute to increase non-communicable diseases, including obesity, diabetes and cardiovascular diseases (39). Therefore, health is no longer the exclusive property of the healthcare sector but is a priority strongly influenced by the life context and, consequently, by the strategies implemented by local governments. Over the last few decades, we recorded a growing interest in urban planning and its relationship with Public Health (16). Researchers and practitioners, both technical and medical, identified the need for an interdisciplinary and trans-disciplinary approach (40), in order to address the main health problems of the city and of contemporary society; there is a need of joint action in order to involve communities starting from the professionals themselves. We should take into account of urban health and sustainability, since the early stages of urban planning, given that urban planning can and must serve as primary prevention and collaboration in promoting health, highlight the need for a holistic approach to city construction. This bottom-up approach is one of the emerging health challenges for all contemporary cities and the related health systems of the nations involved. At the conclusion of the Erice 50 Course "Urban Health. Instruments for health promotion and evaluation of hygienic-and sanitary conditions in urban areas", teachers and students considered it useful and relevant to include these issues within the Degree Courses for Architects, Medical Doctors, Health Technicians, Health Visitors, and in Specialization Schools of Hygiene and Preventive Medicine.

Finally, the Erice 50 Charter "Strategies for Diseases Prevention and Health Promotion in Urban Areas" is consistent and synergistic with the research developments
"Identifying good practices and healthcare performance targets for sustainability and eco-compatibility of buildings construction and / or renovation, with the purpose of the preparation of sanitary hygiene regulations", referring to the project funded by the Ministry of Health CCM 2015 - CUP code B86D15001870001.

\section{Riassunto}

Strategie per la Prevenzione delle Malattie e la Promozione della Salute nelle aree urbane: la Carta di Erice 50

La Carta di Erice 50, dal titolo "Strategie per la Prevenzione delle Malattie e la Promozione della Salute nelle Aree Urbane.", è stata approvata all'unanimità a conclusione del $50^{\circ}$ Corso residenziale in "URBAN HEALTH: Strumenti per la promozione della salute e per la valutazione degli aspetti igienico-sanitari nelle aree urbane", che ha avuto luogo dal 29 Marzo al 2 Aprile 2017 ad Erice, presso la Fondazione e Centro per la Cultura Scientifica "Ettore Majorana" e promosso dall'Internatirnal School of Epidemiology and Preventive Medicine "G. D'Alessandro" e dal Gruppo di Lavoro "Igiene Edilizia" della Società Italiana di Igiene, Medicina Preventiva e Sanità Pubblica (SItI).

$\mathrm{Al}$ termine dell'intensa esperienza didattica, che si è articolata in oltre 20 lezioni frontali, in esercitazioni pratiche ed in momenti di confronto tra Studenti e Docenti coinvolti, i partecipanti hanno individuato i principali elementi di rilevanza in riferimento ai rapporti tra caratteristiche urbane e Sanità Pubblica, rivendicando il ruolo chiave delle strategie di progettazione urbana ai fini della gestione delle azioni di prevenzione delle malattie e di promozione della salute. La Carta di Erice 50 si configura quindi come un Decalogo per le Città in Salute, e come un contenitore di buone pratiche progettuali e di strategie per lo sviluppo di interventi di rigenerazione urbana e per il miglioramento della qualità di vita nella città contemporanea.

Il Decalogo è articolato nei seguenti principali obiettivi strategici: 1. Promuovere una pianificazione urbana che indirizzi i cittadini verso comportamenti salutari; 2 . Migliorare le condizioni di vita nel contesto urbano; 3. Promuovere una città accessibile ed inclusiva; 4 . Realizzare aree urbane resilienti; 5. Favorire lo sviluppo di nuove economie ed occupazione attraverso interventi $\mathrm{di}$ rigenerazione urbana; 6 . Contrastare le disuguaglianze sociali; 7. Migliorare il livello di conoscenza dei diversi stakeholder sui fattori che influenzano la salute nelle 
città; 8 . Assicurare una governance urbana partecipata; 9. Introdurre strumenti prestazionali in grado di misurare la propensione della città a promuovere corretti stili di vita e monitorare lo stato di salute della popolazione; 10. Incoraggiare la condivisione della conoscenza e l'accessibilità all'informazione.

Tutti i partecipanti, infine, hanno sottolineato l'importanza della costituzione di Gruppi multidisciplinari, composti da Medici Igienisti e da altri operatori di Sanità Pubblica, nonché da Tecnici progettisti quali Architetti, Urbanisti ed Ingegneri, per approfondire il tema di ricerca Urban Health.

\section{References}

1. McMichael AJ. The urban environment and health in a world of increasing globalization: issues for developing countries. Bull World Health Organ 2000; 78(9): 1117-26.

2. World Health Organization (WHO). Why urban health matters? Urban health matters. World health day 2000. World Health Organization, 2000. Available on: http://www.who.int/worldhealth-day/2010/media/whd2010background. pdf (Last accessed Tuesday 30 ${ }^{\text {th }}$ May 2017).

3. Coppola L, Ripamonti E, Cereda D, Gelmi G, Pirrone L, Rebecchi A. 2015-2018 Regional Prevention Plan of Lombardy (Northern Italy) and sedentary prevention: a cross-sectional strategy to develop evidence-based programmes. Epidemiol Prev 2016; 40(3-4): 243-8.

4. Capolongo S, Buffoli M, Oppio A. How to assess the effects of urban plans on environment and health. Territorio 2015; (73): 145-51.

5. World Health Organization (WHO). The Ottawa Charter for Health Promotion, 1986. Available on: http://www.who.int/healthpromotion/ conferences/previous/ottawa/en/ (Last accessed Tuesday $30^{\text {th }}$ May 2017).

6. World Health Organization (WHO). Health in all policies, 2006. Available on: http://www.euro. who.int/_data/assets/pdf_file/0007/188809/ Health-in-All-Policies-final.pdf (Last accessed Tuesday $30^{\text {th }}$ May 2017).

7. Capolongo S, D'Alessandro D. Città in salute. Strategie per la tutela e la promozione della salute nei contesti urbani. Santarcangelo di Romagna (RN): Maggioli Editore, 2017.

8. D'Alessandro D, Capolongo S. Ambiente costruito e salute. Milano: Franco Angeli, 2015.
9. Glasgow Centre for Population Health. The built environment and health: an evidence review. Concepts Series 11. November 2013. Available on: http://www.gcph.co.uk/assets/0000/4174/ BP_11_-_Built_environment_and_health_-_ updated.pdf (Last accessed Tuesday 30 ${ }^{\text {th }}$ May 2017).

10. Manifesto "La Salute nelle città: bene comune". Available on: http://www.healthcitythinktank. org/Manifesto-la-salute-nelle-citta-benecomune.pdf (Last accessed Tuesday 30 ${ }^{\text {th }}$ May 2017).

11. WHO-Europe Action Plan for implementation of the European Strategy for prevention and control of non-communicable diseases 2012-2016. Available on: http://apps.who.int/medicinedocs/documents/ s19752en/s19752en.pdf (Last accessed Tuesday $30^{\text {th }}$ May 2017).

12. D'Alessandro D, Buffoli M, Capasso L, Fara GM, Rebecchi A, Capolongo S. Green areas and public health: improving wellbeing and physical activity in the urban context. Epidemiol Prev 2015; 39(4 Suppl 1): 8-13.

13. Forni A e Petronio MG, eds. L'inquinamento atmosferico. Atti delle 7e Giornate italiane mediche dell' ambiente Arezzo 18-19, ottobre 2013. Roma: ENEA, 2014. Available on: http://www.enea.it/it/produzione-scientifica/ edizioni-enea (Last accessed Tuesday $30^{\text {th }}$ May 2017).

14. Oppio A, Bottero M, Giordano G, Arcidiacono A. A multi-methodological evaluation approach for assessing the impact of neighbourhood quality on public health. Epidemiol Prev 2016; 40(3-4): 249-56.

15. Ministero della Salute. Piano Nazionale della Prevenzione (PNP) 2014-2018. Available on: http://www.salute.gov.it/imgs/C_17_ pubblicazioni_2285_allegato.pdf (Last accessed $23^{\text {rd }}$ February 2017).

16. D'Alessandro D, Appolloni L, Capasso L. Public Health and urban planning: a powerful alliance to be enhanced in Italy. Ann Ig 2017; 29(5): 453-63.

17. Sen A. The Idea of Justice. Harvard University Press, 2009.

18. Nussbaum M. Creating Capabilities. The Human Development Approach. Cambridge, London: The Belknap Press of the Harvard University Press, 2011.

19. Blecic I, Cecchini A, Talu V. The capability approach in urban quality of life and urban 
policies: towards a conceptual framework. In: Serreli S, ed. City project and public space. Springer. New York, Dordrecht, Heidelberg, London: Springer, 2013.

20. World Health Organization (WHO). Preventing disease through healthy environments: Towards an estimate of the environmental burden of disease, European Centre for Environment and Health, 2006. Available on: http://www. who.int/quantifying_ehimpacts/publications/ preventingdisease.pdf (Last accessed Tuesday $30^{\text {th }}$ May 2017).

21. Romano-Spica V, Macini P, Galeone D, et al. Adapted Physical Activity for the Promotion of Health and the Prevention of Multisectorial Chronic Diseases: the Erice Charter. Ann Ig 2015; 27(2): 406-14.

22. Wang Y, Chau CK, Ng WY, Leung TM. A review on the effects of physical built environment attributes on enhancing walking and cycling activity levels within residential neighborhoods. Cities 2016; 50: 1-15.

23. Pate RR, Pratt M, Blair SN, et al. Physical activity and public health. A recommendation from the Centers for Disease Control and Prevention and the American College of Sports Medicine. JAMA 1995; 273(5): 402-7.

24. Rebecchi A, Boati L, Oppio A, Buffoli, M, Capolongo S. Measuring the expected increase in cycling in the city of Milan and evaluating the positive effects on the population's health status: A Community-Based Urban Planning experience. Ann Ig 2016; 28(6): 381-91.

25. Speck J. Walkable city: How downtown can save America, one step at a time. Macmillan, New York.

26. Ewing R, Handy S. Measuring the unmeasurable: Urban Design Qualities Related to Walkability. J Urban Design 2009; 14(1): 65-84.

27. Capasso L, Basti A, Savino A, Flacco ME, Manzoli L, D'Alessandro D. Semi-basements used as dwellings: hygienic considerations and analysis of the regulations. Ann Ig 2014; 26(1): 3-9.

28. D'Alessandro D, Raffo M. Adeguare le risposte ai nuovi problemi dell' abitare in una società che cambia. Ann Ig 2011; 23(3): 267-74.

29. Faiella I, Lavecchia L. La povertà energetica in Italia. Questione di Economia e Finanza. Banca d'Italia, 2014: 240

30. World Health Organization (WHO). Global age-friendly cities: a guide. Geneva: World
Health Organization, 2007. Available on: http:// www.who.int/ageing/publications/Global_ age_friendly_cities_Guide_English.pdf (Last accessed Tuesday $30^{\text {th }}$ May 2017).

31. Blecic I, Canu D, Cecchini A, Congiu T, Fancello G. Factors of Perceived Walkability: A Pilot Empirical Study. Computational Science and Its Applications - ICCSA, 2016: 125-37 (Lecture Notes in Computer Science LNCS, vol. 9789).

32. Ministero della salute. Ondate di calore. Available on: http://www.salute.gov.it/portale/ caldo/homeCaldo.jsp (Last accessed Tuesday $30^{\text {th }}$ May 2017).

33. European Environmental Agency. Urban adaptation to climate change in Europe 2016. Transforming cities in a changing climate. EEA Report 2016:12. Available on: http:// www.gppq.fct.pt/h2020/_docs/brochuras/env/ urban-adaptation-report-2016.pdf (Last accessed Tuesday $30^{\text {th }}$ May 2017).

34. Gunderson L, Holling CS, Pritchard L, Peterson GD. Resilience. In: Mooney HA \& Canadell JG. Encyclopedia of global environmental change. SCOPE, 2002. Available on: http://eusoils. jrc.ec.europa.eu/projects/scape/uploads/81/ Holling_Resilience.pdf (Last accessed Tuesday $30^{\text {th }}$ May 2017).

35. Gola M, Capolongo S, Signorelli C, Buffoli M, Rebecchi A. Local health rules and building regulations: a survey on local hygiene and building regulations in italian municiples. Ann Ist Super Sanita 2017; 53(3) [in press].

36. Capolongo S, Lemaire N, Oppio A, Buffoli M, Roue Le Gall A. Action planning for healthy cities: the role of multi-criteria analysis, developed in Italy and France, for assessing health performances in land-use plans and urban development projects. Epidemiol Prev 2016; 40(3-4): 257-64.

37. Capasso L, Campanella F, Costantino C, et al. Knowledge and Training Needs on Built Environment and Indoor Health of Italian Public Health Residents: a National Survey. J Prev Med Hyg 2017; 58(2): E195-9.

38. World Health Organization (WHO). Health as the Pulse of the New Urban Agenda. United Nations Conference on Housing and Sustainable Urban Development. Quito, October 2016.

39. Rydin Y, Bleahu A, Davis M, et al. Shaping cities for health: complexity and the planning of urban 
environments in the 21st century. Lancet 2012; 379: 2079-108.

40. Lawrence RJ. Housing and health: from interdisciplinary principles to transdisciplinary research and practice. Futures 2004; 36(4): 487502.

Corresponding author: Arch. Andrea Rebecchi, Department of Architecture, Built Environment and Construction Engineering, Edificio 14, Via Bonardi 9, 20133 Milano, Italy

e-mail: andrea.rebecchi@polimi.it 